Tohoku J. Exp. Med., 2019, 248, 115-123

\title{
Worsening Health Status among Evacuees: Analysis of Medical Expenditures after the 2011 Great East Japan Earthquake and Nuclear Disaster in Fukushima
}

\author{
Makoto Hasegawa, ${ }^{1}$ Michio Murakami, ${ }^{1}$ Shuhei Nomura, ${ }^{2,3}$ Yoshitake Takebayashi ${ }^{1}$ \\ and Masaharu Tsubokura ${ }^{4,5,6}$ \\ ${ }^{1}$ Department of Health Risk Communication, Fukushima Medical University School of Medicine, Fukushima, \\ Fukushima, Japan \\ ${ }^{2}$ Department of Global Health Policy, Graduate School of Medicine, The University of Tokyo, Tokyo, Japan \\ ${ }^{3}$ Research Center for Community Health, Minamisoma Municipal General Hospital, Minamisoma, Fukushima, \\ Japan \\ ${ }^{4}$ Department of Public Health, Fukushima Medical University School of Medicine, Fukushima, Fukushima, Japan \\ ${ }^{5}$ Department of Radiation Protection, Minamisoma Municipal General Hospital, Minamisoma, Fukushima, Japan \\ ${ }^{6}$ Department of Radiation Protection, Soma Central Hospital, Soma, Fukushima, Japan
}

\begin{abstract}
After Fukushima disaster in 2011, the health status of the region's residents deteriorated. We analyzed the health status, care needs, and access to health services among evacuees and non-evacuees using healthcare expenditure (for self-employed and unemployed individuals aged $<75$ years) and long-term care expenditure (mainly for individuals aged $\geq 65$ years). Fukushima Prefecture was divided into four areas according to their evacuation status: non-EOAs (municipalities that did not include evacuation order areas (EOAs)); EOAs/non-EOAs (municipalities that included both EOAs and non-EOAs); short-term EOAs (municipalities where the EOA designation was lifted in most areas by fiscal year (FY) 2011); and long-term EOAs (municipalities where most EOA designations remained in place until the end of FY 2015). Increases in expenditure on healthcare and long-term care per capita in short-term and long-term EOAs were greater in FY 2015 than the average values in FYs 2008-2010. The increases in expenditure were higher in shortterm and long-term EOAs than those in non-EOAs and EOAs/non-EOAs. The increases in dental health expenditure were attributed to enhanced accessibility to dental health facilities. Furthermore, the evacuations contributed to increases in healthcare and long-term care expenditure, independent of aging and improved accessibly to health facilities. Possible explanations for these increases include the poor health status of the evacuees following the evacuations, reduced availability of informal care provided by family members and neighbors, and reduced patient copayments. The findings highlight the necessity of health promotion among evacuees.
\end{abstract}

Keywords: copayment; Fukushima Daiichi Nuclear Power Station accident; lifestyle-related disease; long-term care insurance; national health insurance

Tohoku J. Exp. Med., 2019 June, 248 (2), 115-123. C 2019 Tohoku University Medical Press

\section{Introduction}

The Great East Japan Earthquake in March 2011 and the subsequent accident at the Tokyo Electric Power Company's Fukushima Daiichi Nuclear Power Station, subsequently referred to as the Fukushima disaster, posed multiple health risks. To prevent radiation exposure, residents living within $20 \mathrm{~km}$ of the Fukushima Daiichi Nuclear Power Station and within $10 \mathrm{~km}$ of the Fukushima Daini Nuclear Power Station were forced to evacuate on March 12, 2011. Further, residents who were likely to have an additional effective dose of $\geq 20 \mathrm{mSv} / \mathrm{year}$ were also ordered to evacuate on April 22, 2011. After the lifting of evacuation orders, some people have now started returning to hometown. As of October 2015, 44,094 people (approximately $2 \%$ of the total population in Fukushima Prefecture) were evacuated from Fukushima Prefecture to other prefectures (Fukushima Prefecture 2019). The coastal area of Miyagi Prefecture, located north of Fukushima, was disproportionally affected by the tsunami that struck after the Great East Japan Earthquake, with loss of housing, disruption of access to internal medicine, and adverse effects on

Received February 21, 2019; revised and accepted June 12, 2019. Published online June 26, 2019; doi: 10.1620/tjem.248.115.

Correspondence: Michio Murakami, Department of Health Risk Communication, Fukushima Medical University School of Medicine,

1 Hikarigaoka, Fukushima, Fukushima 960-1295, Japan.

e-mail: michio@fmu.ac.jp 
daily activities of living (Tsuboya et al. 2017). According to previous research, community-level social capital (i.e., bonds of trust between community members, as well as norms of mutual assistance) mitigated the impact of housing damage on cognitive decline (Hikichi et al. 2018). Following the Fukushima disaster, evacuees, especially those who had lived in evacuation order areas (EOAs), in Fukushima Prefecture were at risk of multiple health problems, including severe mental health issues such as depression and post-traumatic stress disorder (Yoshida et al. 2016). Subsequent research highlighted the urgent need for long-term health supports for evacuees (Fukunaga and Kumakawa 2015). Lifestyle-related diseases, such as diabetes and hyperlipidemia, emerged as major health issues in EOAs in the chronic phase after the disaster (Ebner et al. 2016; Nomura et al. 2016; Ohira et al. 2017; Murakami et al. 2017).

Expenditure on healthcare and long-term care is useful to investigate health status, care needs, and access to health services (Uchimura et al. 2014; Morita et al. 2016; Kent et al. 2017; Matsuyama et al. 2018). All Japanese citizens have public health insurance, whereas long-term care insurances target elders who need care (e.g., meal assistance). Increased expenditure on healthcare and long-term care reflects changes in care needs or access to health services. In the case of the Fukushima disaster, excess weight was associated with higher healthcare costs (Kent et al. 2017). Uchimura et al. (2014) reported a decline in long-term care expenditure for 1-5 months immediately after the Fukushima disaster and attributed this decline to upheaval (e.g., losses of their house) related to the disaster. Morita et al. (2016) reported that the total expenditure on long-term care services in Minamisoma City, an EOA, was 50\% higher in 2014 than the pre-disaster level in 2009. They argued that reduced availability of informal care provided by younger family members might explain this rise. In terms of health insurance, Matsuyama et al. (2018) reported that the copayment exemption policy helped to increase healthcare service utilization in Miyagi Prefecture after the Great East Japan Earthquake.

No studies have systematically evaluated temporal changes in expenditure on healthcare and long-term care in pre- versus post-disaster periods. In particular, no detailed studies were performed to compare healthcare and longterm care between evacuees and non-evacuees, despite their health status difference (Ebner et al. 2016; Nomura et al. 2016; Ohira et al. 2017; Murakami et al. 2017). Detailed investigations, including comparative analyses of expenditure on healthcare and long-term care among evacuees and non-evacuees, would enhance understanding of temporal changes post-disaster. Such studies would provide information on care needs and access to health services post-disaster, as well as differences in the needs of evacuees versus those of non-evacuees.

The objective of this study was to explore the health status, care needs and access to health services after the
Fukushima disaster among evacuees and non-evacuees by examining two types of medical expenditure (i.e., healthcare and long-term care) and identifying factors associated with changes in expenditure post-disaster.

This paper was prepared after an English translation and the addition of analyses, results, and discussion to an A4 one-page abstract presented at the Proceedings of the Society for Risk Analysis-Japan Annual Meeting (Hasegawa et al. 2017).

\section{Methods}

Insurance and care systems in Japan and the copayment exemption in affected areas after the Fukushima disaster

Self-employed and unemployed individuals aged $<75$ years have National Health Insurance (NHI), employed citizens aged $<75$ years have employees' health insurance, and those aged $\geq 75$ years have long-life medical care. In principle, insurance premiums and copayment rates $(10-30 \%)$ depend on age, occupation, number of dependents, and income level. NHI is a major public health insurer run by municipal governments. It insured $32.0 \%$ of individuals aged $<75$ years in fiscal year (FY) 2015 (Ministry of Health, Labour and Welfare 2018c). In this study, the FY was from April to March, unless indicated otherwise.

Long-term care insurance, also run by municipal governments, targets two age groups: individuals aged 40-64 years (secondary insured subscribers) and individuals aged $\geq 65$ years (primary insured subscribers). Primary insured subscribers are the main recipients of long-term care, with $17.9 \%$ of primary insured subscribers certified to receive long-term care in FY 2015 (Ministry of Health, Labour and Welfare 2018b).

As NHI and long-term care insurance are linked to the Basic Resident Register, the insurance data reflect the place the insured persons lived before the Fukushima disaster.

After the Fukushima disaster, individuals in EOAs were exempted from the copayment for NHI and long-term care insurance. Since FY 2014, high-income earners have been excluded from the exemption in areas where evacuation orders have been lifted. The present study did not include any data from other health insurers.

Data

We analyzed freely available public data provided by the Ministry of Health, Labour and Welfare (2018a, b, c, d, e, f), Ministry of Internal Affairs and Communications (2018), and Statistics Bureau, Ministry of Internal Affairs and Communications (2017), Hirono Town (2017), Minamisoma City (2019), and Reconstruction Agency (2019). The data included the following: expenditure on healthcare for NHI subscribers and long-term care for individuals aged $\geq 65$ years, the population aging rate of NHI subscribers aged 65-74 years, the rate of long-term care insurance primary insured subscribers aged 75 years and older, the percentage of males, and the NHI subscriber's income per capita.

In the analysis of regional differences in expenditure on healthcare, expenditure was divided into inpatient, outpatient (including dispensing), and dentistry (Ministry of Health, Labour and Welfare, 2018a). We included expenditure data from FYs 2008-2015 and excluded FY 2010 data on long-term care because the data were incomplete. Temporal changes in expenditure each year were calculated by dividing the value by the average for FYs 2008-2010 for a comparison before and after the disaster. 


\section{Study region}

The study region was Fukushima Prefecture. As the timing of lifting of EOAs differed among municipalities, the study sites were divided into four categories according to their evacuation status: nonEOAs (i.e., municipalities that did not included EOAs); EOAs/nonEOAs (i.e., municipalities including both EOAs and non-EOAs); short-term EOAs (i.e., municipalities where the EOA designation was lifted in most areas by FY 2011); and long-term EOAs (i.e., municipalities where most EOA designations remained in place until the end of FY 2015). EOAs/non-EOAs included the Tamura City, where the EOA designation was lifted in stages between 30 September 2011 and 1 April 2014; Minamisoma City, where the designation was partly lifted by 30 September 2011 and 28 December 2014; Date City, where the EOA designation was lifted by 30 March 2012; and Kawamata Town; where the designation was not lifted by the end of FY 2015. In short-term EOAs, the designation was lifted in most areas by FY 2011. In Hirono Town, the EOA designation was lifted by 30 September 2011. In Kawauchi Village, the EOA designation was lifted by 30 September 2011, 30 March 2012, and 1 October 2014. In long-term EOAs, the designation remained in place until the end of FY 2015. In Naraha Town, the designation was lifted by 30 September 2011 and 5 September 2015. In Tomioka Town, Okuma Town, Futaba Town, Namie Town, Katsurao Village, and Iitate Village, the EOA designation was not lifted by the end of FY 2015 (Ministry of Economy, Trade, and Industry 2018; Fukushima Prefecture 2018) (Fig. 1). Non-EOAs were regarded as controls.

Analysis

We performed multiple linear regression analysis for the whole Fukushima Prefecture and three EOA categories (i.e., Fukushima Prefecture except non-EOAs) separately, as similar with Matsuyama et al. (2018). The outcome variables were municipality-level data: changes in total health care expenditure, inpatient health care expenditure, outpatient health care expenditure, dental health care expendi- ture, and long-term care expenditure per capita. The outcomes were rate differences from pre-disaster (2008-2010 or 2008-2009) to 2015. To assess the changes in total health care expenditure, inpatient health care expenditure, and outpatient health care expenditure, the explanatory variables in the analyses among Fukushima Prefecture were as follows: the evacuation rate in FY 2015, except three municipalities due to data availability (i.e., Naraha Town in 2013 FY; Katsurao Village in 2013 FY; Minamisoma City in 2016 FY) (Hirono Town 2017; Minamisoma City 2019; Reconstruction Agency 2019), changes in the rate of NHI subscribers aged 65-74 years from 2010 to 2015 , changes in the number of doctors per capita from 2010 to average of 2014 and 2016, changes in the number of hospitals per capita from 2010 to 2015, and changes in the number of clinics per capita from 2010 to 2015. The evacuation rate in Date City was assumed to $0 \%$. For dental health care expenditure, changes in the number of dentists from 2010 to average of 2014 and 2016 and changes in the number of dental clinics from 2010 to 2015 were used instead of changes in the number of doctors per capita, changes in the number of hospitals per capita, and changes in the number of clinics per capita. For long-term care expenditure, the outcome variables were the evacuation rate, changes in the rate of long-term care insurance subscribers aged 75 years or over from 2008-2009 to 2015, and changes in the capacities (i.e., number of residents) of long-term care insurance facilities per capita from 2010 to 2015 . Due to the small number of municipalities, the explanatory variables in the analyses of Fukushima Prefecture except non-EOAs. included only the following: the evacuation rate, changes in the number of doctors per capita, changes in the number of dentists per capita, changes in the capacities of long-term care insurance facilities per capita, and changes in the rate of long-term care insurance subscribers aged 75 years or over. The changes in the rate of NHI subscribers aged 65-74 years were not included due to strong correlations between changes in this variable and the evacuation rate (Pearson's coefficient of correlation: -0.89 ). We supposed that the change in the number of hospitals, clinics,

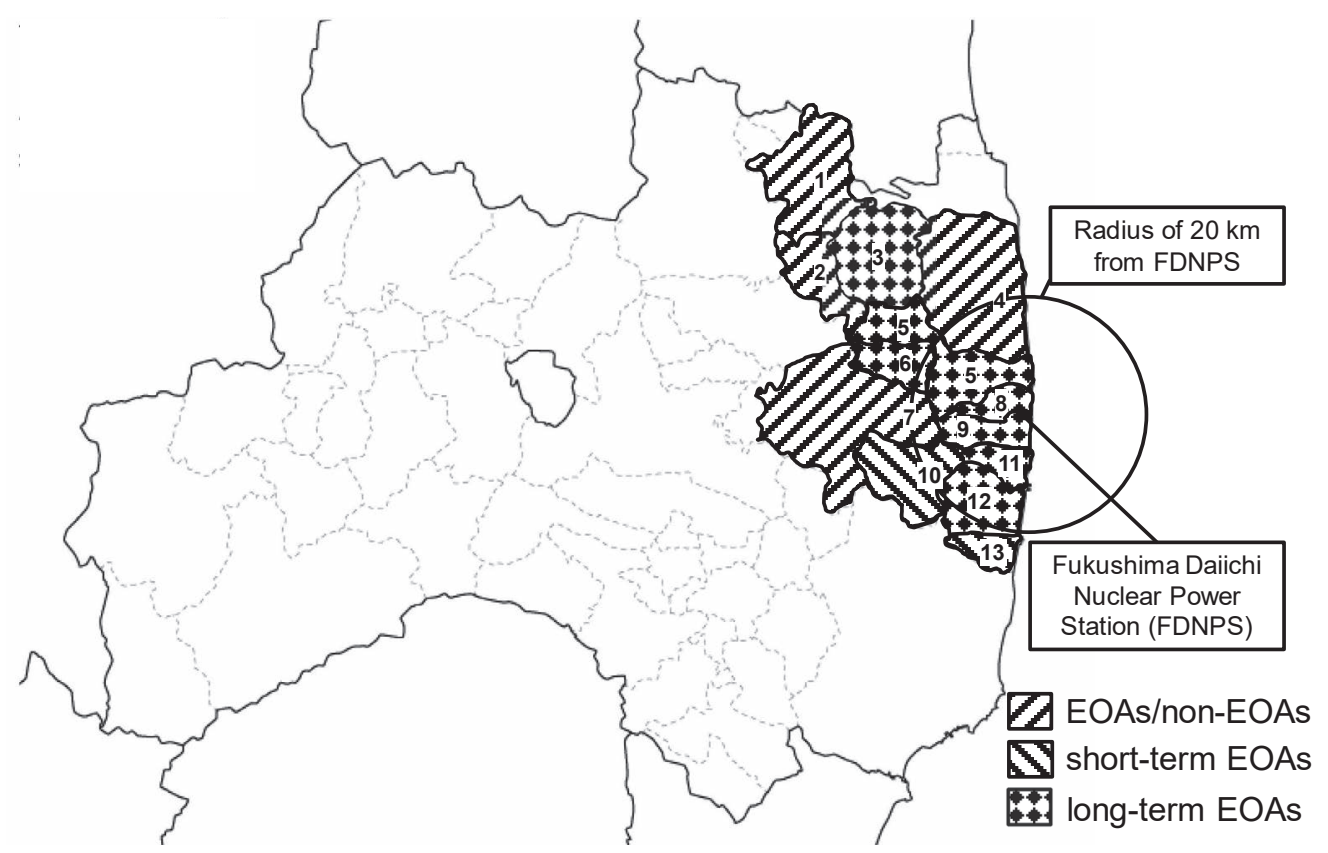

Fig. 1. Location of analyzed regions, Fukushima Prefecture.

1. Date City, 2. Kawamata Town, 3. Iitate Village, 4. Minamisoma City, 5. Namie Town, 6. Katsurao Village, 7. Tamura

City, 8. Futaba Town, 9. Okuma Town, 10. Kawauchi Village, 11. Tomioka Town, 12. Naraha Town, 13. Hirono Town. 
capacities of long-term care insurance facilities, doctors, and dentists per capita reflected accessibility to health facilities.

Data from questionnaire surveys and on official websites of the municipalities were used to estimate the proportion of people relocated from EOAs to other municipalities after the disaster (Hirono Town 2017; Minamisoma City 2019; Reconstruction Agency 2019). In Minamisoma City, the proportion of people relocated to other municipalities was only $7.6 \%$, and no information was available on the relocated municipalities other than the original hometown. Thus, the values in Minamisoma City were not corrected by the values in other municipalities. The values for unspecific municipalities (i.e., "other municipalities" shown in the report due to the small proportion) in Fukushima Prefecture and outside Fukushima Prefecture followed the average values in the Fukushima prefectural and the whole of Japan, respectively. The analysis revealed low multicollinearity, with a variance inflation factor of 1.00-3.08.

IBM SPSS Statistics 25 (IBM, Armonk, NY, USA) were used for data analysis. Ethics approval was not necessary, as all the data used are freely available to the public.

\section{Results}

In terms of demographic data, there were no marked differences among the four evacuation categories in Fukushima Prefecture (Fig. 2). The rates of NHI subscribers aged 65-74 years in non-EOAs and EOAs/non-EOAs increased slightly from FY 2008 to FY 2015, but the overall increase in short-term and long-term EOAs was small (Fig.
2A). Changes in the rate of long-term care insurance subscribers aged 75 years or over and in the percentage of males were similar in the four evacuation categories (Fig. 2B, C). NHI subscribers' incomes per capita decreased, especially in FY 2012 but recovered by 2015 FY (Fig. 2D).

We compared changes in expenditure on healthcare and long-term care per capita in all years (Fig. 3) and the FY 2015 (Table 1) with the average for FYs 2008-2010. There were marked increases in expenditure on both total healthcare and long-term care after the Fukushima disaster in both short-term and long-term EOAs (Fig. 3A, E). Expenditure on healthcare in FY 2015 increased by 43.1\% in long-term EOAs and by $43.3 \%$ in short-term EOAs (Table 1) relative to the average values for FYs 2008-2010. Expenditure on long-term care in FY 2015 increased by $62.5 \%$ and $47.4 \%$, respectively.

Expenditure on outpatient healthcare increased steadily in all four evacuation categories (Fig. 3C). Before FY 2015, expenditure on inpatient healthcare in short-term EOAs did not change greatly, but it increased by $35.3 \%$ in FY 2015 (Fig. 3B). In FY 2011, expenditure on dental care increased by $95.3 \%$ and $120.7 \%$ in short-term and longterm EOAs, respectively, and then gradually decreased to $+28.7 \%$ and $+62.8 \%$, respectively (Fig. $3 \mathrm{D}$ ). Expenditure on long-term care in both short-term and long-term EOAs increased until FY 2013 and then stabilized (short-term EOAs, $+47.4 \%$; long-term EOAs, $+62.5 \%$; Fig. 3E).
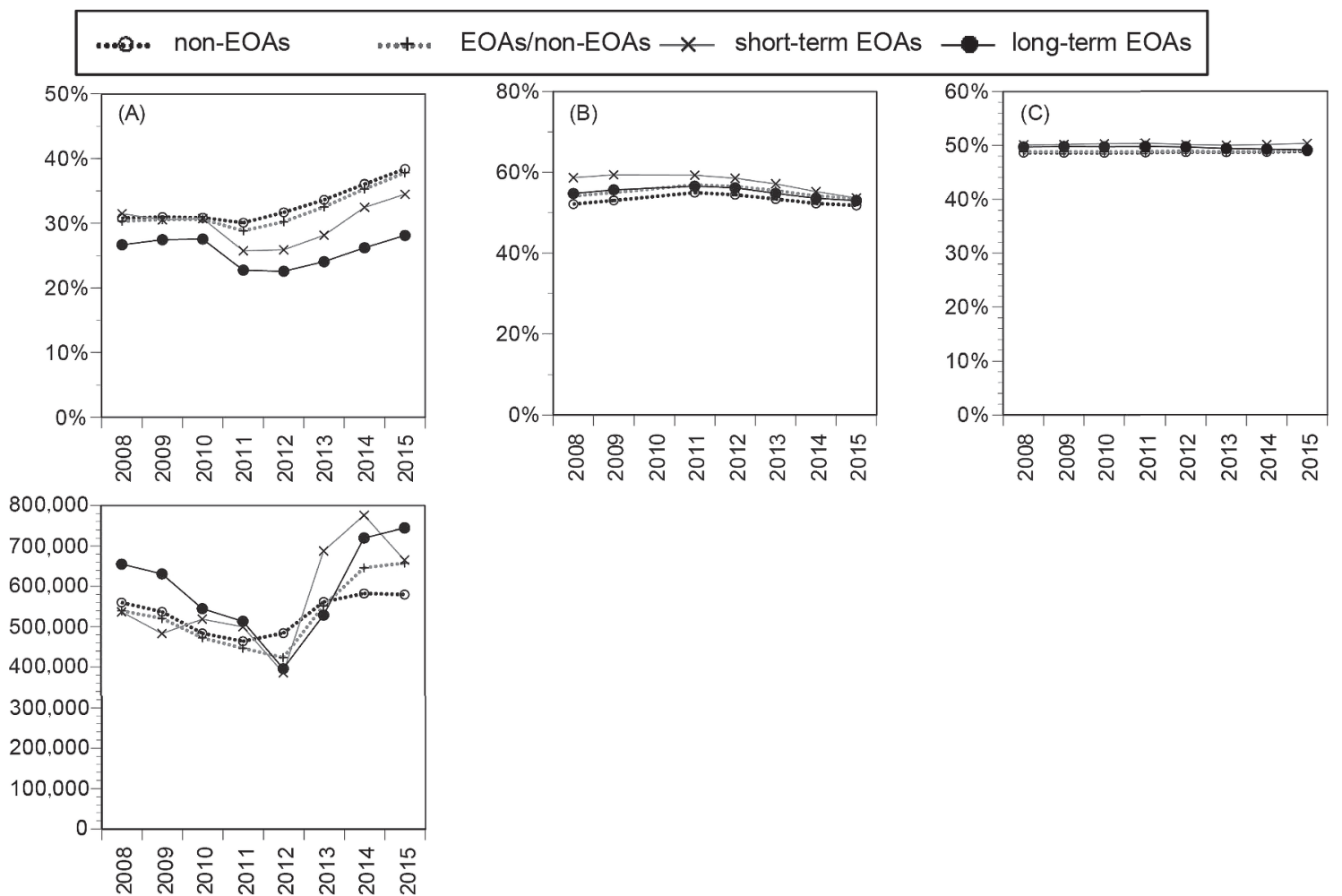

Fig. 2. Temporal changes in demographic date in four evacuation categories in Fukushima Prefecture.

(A) Rates of National Health Insurance (NHI) subscribers aged 65-74 years. (B) Rates of long-term care insurance subscribers aged 75 years or over, (C) Percentage of males. (D) Annual income per National Health Insurance (NHI) subscribers aged 65-74 years. 
Table 1. Increases in expenditure on health and long-term care per capita in FY 2015 relative to the average of FYs 2008-2010 in four evacuation categories in Fukushima Prefecture.

\begin{tabular}{|c|c|c|c|c|}
\hline & non-EOAs & $\begin{array}{c}\text { EOAs/ } \\
\text { non-EOAs }\end{array}$ & $\begin{array}{l}\text { short-term } \\
\text { EOAs }\end{array}$ & $\begin{array}{l}\text { long-term } \\
\text { EOAs }\end{array}$ \\
\hline $\begin{array}{l}\text { total health care } \\
\text { expenditure }\end{array}$ & $\begin{array}{c}18.3 \% \\
(51,254 \mathrm{JPY})\end{array}$ & $\begin{array}{c}24.9 \% \\
(68,905 \mathrm{JPY})\end{array}$ & $\begin{array}{c}43.3 \% \\
(141,498 \mathrm{JPY})\end{array}$ & $\begin{array}{c}43.1 \% \\
(120,184 \mathrm{JPY})\end{array}$ \\
\hline $\begin{array}{l}\text { inpatient health } \\
\text { care expenditure }\end{array}$ & $\begin{array}{c}13.7 \% \\
(15,324 \mathrm{JPY})\end{array}$ & $\begin{array}{c}13.6 \% \\
(15,252 \mathrm{JPY})\end{array}$ & $\begin{array}{c}35.3 \% \\
(52,014 \mathrm{JPY})\end{array}$ & $\begin{array}{c}11.7 \% \\
(13,935 \mathrm{JPY})\end{array}$ \\
\hline $\begin{array}{l}\text { outpatient health } \\
\text { care expenditure }\end{array}$ & $\begin{array}{c}22.8 \% \\
(34,076 \mathrm{JPY})\end{array}$ & $\begin{array}{c}34.5 \% \\
(50,639 \mathrm{JPY})\end{array}$ & $\begin{array}{c}52.3 \% \\
(83,962 \mathrm{JPY})\end{array}$ & $\begin{array}{c}66.9 \% \\
(94,482 \mathrm{JPY})\end{array}$ \\
\hline $\begin{array}{l}\text { dental health care } \\
\text { expenditure }\end{array}$ & $\begin{array}{c}9.5 \% \\
(1,855 \mathrm{JPY})\end{array}$ & $\begin{array}{c}16.3 \% \\
(3,014 \mathrm{JPY})\end{array}$ & $\begin{array}{c}28.7 \% \\
(5,522 \mathrm{JPY})\end{array}$ & $\begin{array}{c}62.8 \% \\
(11,768 \mathrm{JPY})\end{array}$ \\
\hline $\begin{array}{l}\text { total long-term } \\
\text { care expenditure }\end{array}$ & $\begin{array}{c}22.8 \% \\
(51,736 \mathrm{JPY})\end{array}$ & $\begin{array}{c}27.5 \% \\
(60,663 \mathrm{JPY})\end{array}$ & $\begin{array}{c}47.4 \% \\
(96,036 \mathrm{JPY})\end{array}$ & $\begin{array}{c}62.5 \% \\
(144,282 \mathrm{JPY})\end{array}$ \\
\hline
\end{tabular}

$1 \mathrm{JPY}=0.0083 \mathrm{USD}$ as of 2015 .

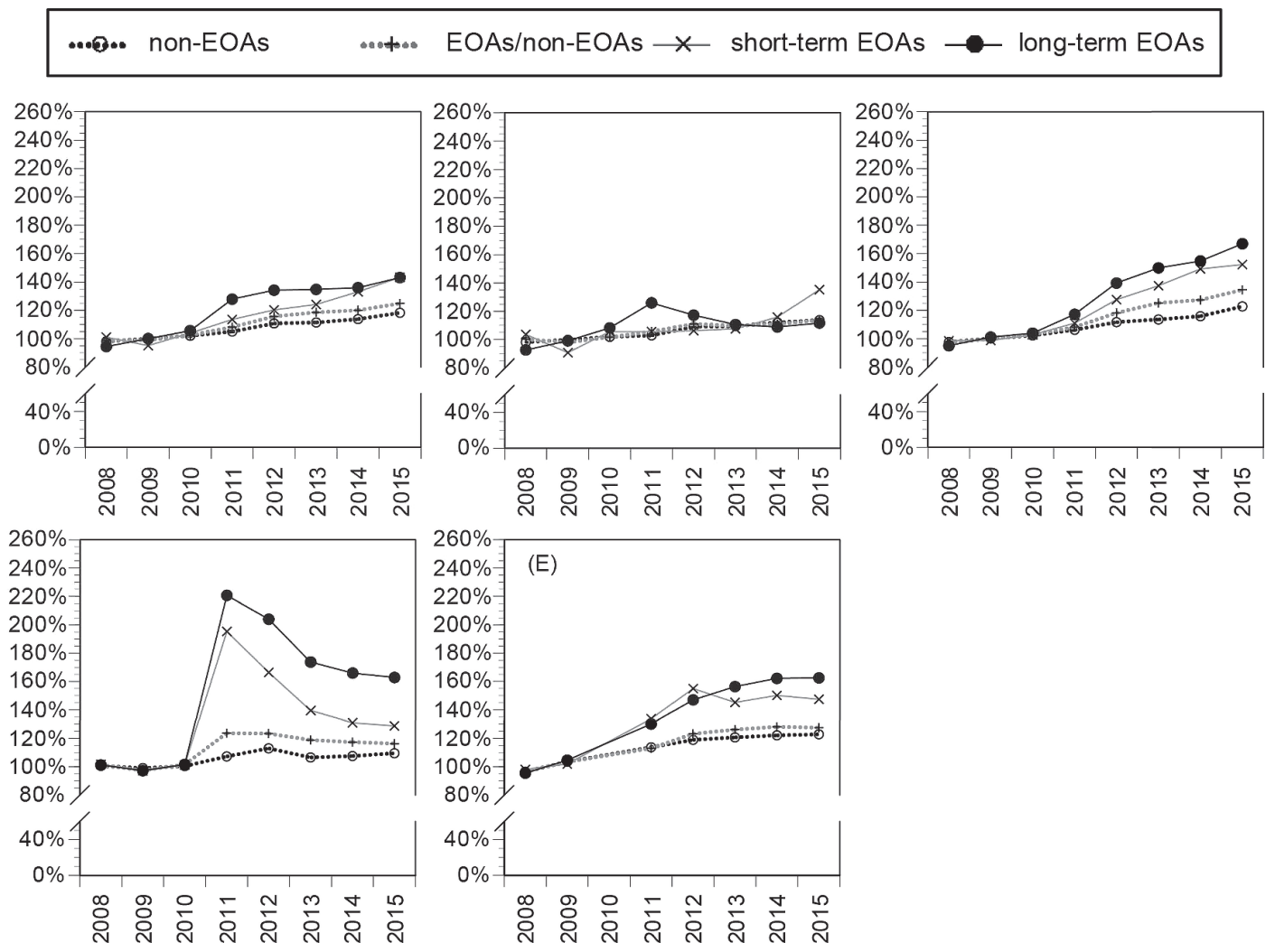

Fig. 3. Temporal changes in expenditure in four evacuation categories in Fukushima Prefecture.

(A-D) Expenditure on healthcare per capita of NHI subscribers. (A) Total healthcare expenditure (B) Inpatient healthcare expenditure (C) Outpatient healthcare expenditure (D) Dental healthcare expenditure. (A-D) $100 \%$ corresponds to the average of FYs 2008-2010. (E) Expenditure on long-term care per capita of people aged $\geq 65$ years. $100 \%$ corresponds to the average of FYs 2008 and 2009. 
The multiple linear regression analyses of data from the whole of Fukushima Prefecture showed significant positive associations between the evacuation rate and expenditure, except for inpatient expenditure $(\mathrm{P}<0.001)$ (Table 2). The rates of NHI subscribers aged 65-74 years showed a significant positive association with total healthcare expenditure and outpatient healthcare expenditure $(\mathrm{P}<$ $0.05)$. The number of dentists per capita was significantly and positively associated with dental healthcare expenditure $(\mathrm{P}<0.05)$. The change in the rate of long-term care insurance subscribers aged 75 years and older displayed a significant positive association with the change in long-term care expenditure $(\mathrm{P}<0.001)$, whereas the change in the capacities of long-term care insurance facilities showed a significantly negative association $(\mathrm{P}<0.05)$.

As shown by the multiple linear regression analyses of the data for Fukushima Prefecture except non-EOAs, the evacuation rate was significantly and positively associated with total healthcare expenditure, outpatient healthcare expenditure, dental healthcare expenditure, and long-term care expenditure per capita $(\mathrm{P}<0.05)$ (Table 3$)$. The number of dentists showed a borderline significant positive association with dental healthcare expenditure $(\mathrm{P}=0.06)$. The change in the rate of long-term care insurance subscribers aged 75 years or over showed a borderline significant positive association with long-term care expenditure $(\mathrm{P}=$ $0.08)$.

Table 2. Associations of factors to increases in expenditure on healthcare and long-term care per capita in the whole of Fukushima Prefecture thorough multiple linear regression analysis.

\begin{tabular}{|c|c|c|c|c|c|c|c|c|c|c|c|c|c|c|c|}
\hline \multirow[b]{3}{*}{ explanatory variables } & \multirow{2}{*}{\multicolumn{3}{|c|}{ Total healthcare }} & \multicolumn{9}{|c|}{ Outcome variables } & \multirow{2}{*}{\multicolumn{3}{|c|}{ Long-term care }} \\
\hline & & & & Inpatient $\mathrm{h}$ & althcar & & Outpatier & nealthcar & & Dental & ealthcar & & & & \\
\hline & $\begin{array}{c}\mathrm{B} \\
(95 \% \mathrm{Cl})\end{array}$ & $\beta$ & $\mathrm{P}$ & $\begin{array}{c}\mathrm{B} \\
(95 \% \mathrm{Cl})\end{array}$ & $\beta$ & $\mathrm{P}$ & $\begin{array}{c}\mathrm{B} \\
(95 \% \mathrm{Cl})\end{array}$ & $\beta$ & $P$ & $\begin{array}{c}\mathrm{B} \\
(95 \% \mathrm{Cl})\end{array}$ & $\beta$ & $P$ & $\begin{array}{c}\mathrm{B} \\
(95 \% \mathrm{CI})\end{array}$ & $\beta$ & $P$ \\
\hline constant & $\begin{array}{c}0.07 \\
(-0.057-0.20)\end{array}$ & - & 0.27 & $\begin{array}{c}0.079 \\
(-0.075-0.23)\end{array}$ & - & 0.31 & $\begin{array}{c}0.058 \\
(-0.12-0.23)\end{array}$ & - & 0.51 & $\begin{array}{c}0.055 \\
(-0.072-0.18)\end{array}$ & - & 0.39 & $\begin{array}{c}0.47 \\
(0.36-0.58)\end{array}$ & - & $<0.001$ \\
\hline Evacuation rate & $\begin{array}{c}0.35 \\
(0.21-0.48)\end{array}$ & 0.90 & $<0.001$ & $\begin{array}{c}0.052 \\
(-0.11-0.21)\end{array}$ & 0.14 & 0.52 & $\begin{array}{c}0.58 \\
(0.39-0.76)\end{array}$ & 0.99 & $<0.001$ & $\begin{array}{c}0.54 \\
(0.40-0.69)\end{array}$ & 0.88 & $<0.001$ & $\begin{array}{c}0.46 \\
(0.24-0.69)\end{array}$ & 0.44 & $<0.001$ \\
\hline $\mathrm{NHI}$ aging ${ }^{\mathrm{a}}$ & $\begin{array}{c}1.9 \\
(0.39-3.5)\end{array}$ & 0.47 & 0.02 & $\begin{array}{c}1.2 \\
(-0.65-3.1)\end{array}$ & 0.30 & 0.19 & $\begin{array}{c}2.7 \\
(0.61-4.8)\end{array}$ & 0.44 & 0.01 & $\begin{array}{c}0.71 \\
(-0.85-2.3)\end{array}$ & 0.11 & 0.37 & - & - & - \\
\hline Long-term care aging ${ }^{\mathrm{b}}$ & - & - & - & - & - & - & - & - & - & - & - & - & $\begin{array}{c}6.6 \\
(3.9-9.3)\end{array}$ & 0.53 & $<0.001$ \\
\hline The number of doctors ${ }^{c}$ & $\begin{array}{c}80 \\
(-45-200)\end{array}$ & 0.17 & 0.20 & $\begin{array}{c}130 \\
(-26-280)\end{array}$ & 0.27 & 0.10 & $\begin{array}{c}89 \\
(-81-260)\end{array}$ & 0.13 & 0.30 & - & - & - & - & - & - \\
\hline The number of dentists ${ }^{\mathrm{d}}$ & - & - & - & - & - & - & - & - & - & $\begin{array}{c}390 \\
(32-760)\end{array}$ & 0.22 & 0.03 & - & - & - \\
\hline The number of hospitals ${ }^{e}$ & $\begin{array}{c}410 \\
(-1,000-1,800)\end{array}$ & 0.07 & 0.57 & $\begin{array}{c}460 \\
(-1,300-2,200)\end{array}$ & 0.08 & 0.60 & $\begin{array}{c}240 \\
(-1,700-2,200)\end{array}$ & 0.03 & 0.81 & - & - & - & - & - & - \\
\hline The number of clinics ${ }^{f}$ & $\begin{array}{c}9.1 \\
(-250-270)\end{array}$ & 0.01 & 0.94 & $\begin{array}{c}5.8 \\
(-310-330)\end{array}$ & 0.01 & 0.97 & $\begin{array}{c}-11 \\
(-370-350)\end{array}$ & -0.01 & 0.95 & - & - & - & - & - & - \\
\hline The number of dental clinics ${ }^{\mathrm{g}}$ & - & - & - & - & - & - & - & - & - & $\begin{array}{c}-320 \\
(-810-170)\end{array}$ & -0.13 & 0.20 & - & - & - \\
\hline Long-term care insurance facilities ${ }^{\mathrm{h}}$ & - & - & - & - & - & - & - & - & - & - & - & - & $\begin{array}{c}-19 \\
(-37-1.8)\end{array}$ & -0.24 & 0.03 \\
\hline
\end{tabular}

athe change in the rate of NHI subscribers aged 65-74 years.

bthe change in the rate of long-term care insurance subscribers aged 75 years or over.

cthe change in the number of doctors per capita.

dthe change in the number of dentists per capita.

ethe change in the number of hospitals per capita.

the change in the number of clinics per capita.

sthe change in the number of dental clinics per capita.

${ }^{\text {ht }}$ the change in the capacities of long-term care insurance facilities per capita.

$\mathrm{B}$, unstandardized regression coefficient; $\beta$, standardized regression coefficient; $\mathrm{CI}$, confidence interval.

Table 3. Associations of factors to increases in expenditure on healthcare and long-term care per capita in Fukushima Prefecture except non-EOAs thorough multiple linear regression analysis.

\begin{tabular}{|c|c|c|c|c|c|c|c|c|c|c|c|c|c|c|c|}
\hline \multirow[b]{3}{*}{ explanatory variables } & \multirow{2}{*}{\multicolumn{3}{|c|}{ Total healthcare }} & \multicolumn{9}{|c|}{ Outcome variables } & \multirow{2}{*}{\multicolumn{3}{|c|}{ Long-term care }} \\
\hline & & & & Inpatier & healthcar & & Outpatic & healtho & & Dental 1 & ealthcar & & & & \\
\hline & $\begin{array}{c}\mathrm{B} \\
(95 \% \mathrm{Cl})\end{array}$ & $\beta$ & $\mathrm{P}$ & $\begin{array}{c}\text { B } \\
(95 \% \mathrm{Cl})\end{array}$ & $\beta$ & $P$ & $\begin{array}{c}\mathrm{B} \\
(95 \% \mathrm{Cl})\end{array}$ & $\beta$ & $P$ & $\begin{array}{c}\text { B } \\
(95 \% \mathrm{Cl})\end{array}$ & $\beta$ & $P$ & $\begin{array}{c}\mathrm{B} \\
(95 \% \mathrm{CI})\end{array}$ & $\beta$ & $P$ \\
\hline constant & $\begin{array}{c}0.24 \\
(0.14-0.34)\end{array}$ & - & $<0.001$ & $\begin{array}{c}0.19 \\
(0.023-0.36)\end{array}$ & - & 0.03 & $\begin{array}{c}0.30 \\
(0.19-0.40)\end{array}$ & - & $<0.001$ & $\begin{array}{c}0.11 \\
(-0.043-0.25)\end{array}$ & - & 0.14 & $\begin{array}{c}0.50 \\
(0.084-0.93)\end{array}$ & - & 0.02 \\
\hline Evacuation rate & $\begin{array}{c}0.19 \\
(0.065-0.31)\end{array}$ & 0.73 & 0.007 & $\begin{array}{c}-0.048 \\
(-0.26-0.16)\end{array}$ & -0.16 & 0.62 & $\begin{array}{c}0.36 \\
(0.22-0.49)\end{array}$ & 0.88 & $<0.001$ & $\begin{array}{c}0.50 \\
(0.31-0.70)\end{array}$ & 0.82 & $<0.001$ & $\begin{array}{c}0.51 \\
(0.071-0.95)\end{array}$ & 0.56 & 0.03 \\
\hline The number of doctors ${ }^{a}$ & $\begin{array}{c}54 \\
(-380-490)\end{array}$ & 0.06 & 0.79 & $\begin{array}{c}67 \\
(-680-810)\end{array}$ & 0.06 & 0.84 & $\begin{array}{c}72 \\
(-410-550)\end{array}$ & 0.05 & 0.74 & - & - & - & - & - & - \\
\hline The number of dentists ${ }^{\mathrm{b}}$ & - & - & - & - & - & - & - & - & - & $\begin{array}{c}1,400 \\
(-81-2,800)\end{array}$ & 0.30 & 0.06 & - & - & - \\
\hline Long-term care insurance facilities ${ }^{c}$ & - & - & - & - & - & - & - & - & - & $\begin{array}{l}- \\
-\end{array}$ & - & - & $\begin{array}{c}-55 \\
(-140-33)\end{array}$ & -0.30 & 0.19 \\
\hline Long-term care aging $^{\mathrm{d}}$ & - & - & - & - & - & - & - & - & - & - & - & - & $\begin{array}{c}6.5 \\
(-1.1-14)\end{array}$ & 0.41 & 0.08 \\
\hline
\end{tabular}

athe change in the number of doctors per capita.

bthe change in the number of dentists per capita.

cthe change in the capacities of long-term care insurance facilities per capita.

${ }^{\mathrm{d}}$ the change in the rate of long-term care insurance subscribers aged 75 years or over.

$\mathrm{B}$, unstandardized regression coefficient; $\beta$, standardized regression coefficient; $\mathrm{CI}$, confidence interval. 


\section{Discussion}

Overall, expenditure on both healthcare and long-term care increased in both short-term and long-term EOAs after the Fukushima disaster, and the rate of increase in expenditure was higher in short-term and long-term EOAs than in non-EOAs and EOAs/non-EOAs. There were differences in the patterns of temporal change among the healthcare types.

The multiple regression analyses of data from the whole of Fukushima Prefecture and Fukushima Prefecture except non-EOAs revealed that evacuation showed a significant positive association with healthcare and longterm care expenditure, except inpatient healthcare expenditure. The results, adjusted for aging indicators (i.e., the rate of NHI subscribers aged 65-74 years or the rate of long-term care insurance subscribers aged 75 years or older), indicated that the increases in healthcare and longterm care expenditure were not attributable only to aging but also evacuation. Although the number of dentists was positively related to dental health care expenditure, healthcare expenditure was not significantly associated with accessibility to health facilities (e.g., the numbers of doctors, hospitals, and clinics per capita). The observed increases in dental health expenditure could be attributed to the ease of accessibility to dental health facilities. There are geographical and economical barriers to access to dental healthcare facilities in Japan (Hamano et al. 2017; Nishide et al. 2017). Given the exemption from the copayment and improved accessibility to health facilities, it is reasonable to speculate that both the number of dentists and the evacuation rate were related to dental healthcare expenditure. In contrast, expenditure on other types of healthcare might not necessarily be related to accessibility.

Regarding long-term care in the whole of Fukushima Prefecture, the large capacities of long-term care insurance facilities were associated with decreases in long-term care expenditure. One possible explanation for this finding was that improved access to long-term care insurance facilities improved cost performances.

As discussed earlier, the increases in healthcare and long-term care expenditure were significant among evacuees, independent of accessibility to healthcare facilities. This finding may be explained by the exemption from the healthcare copayment and long-term care expenditure by evacuees improving adherence to medication instructions (Maciejewski et al. 2010; Choudhry et al. 2011; Campbell et al. 2014). In particular, expenditure on dental care increased dramatically after the disaster, followed by decreases in expenditure in short-term and longterm EOAs. This was most likely attributable to the copayment exemption for evacuees. As the health status of the evacuees worsened after the disaster (Ebner et al. 2016; Nomura et al. 2016; Ohira et al. 2017; Murakami et al. 2017), the increases in expenditure in both short-term and long-term EOAs may also be attributable to the poor health status of the evacuees. In addition, the increases in expenditure on long-term care might be attributable to reduced availability of informal care provided by younger family members and neighbors following evacuation (Morita et al. 2016).

The copayment exemption was beneficial in promoting evacuees' health. The reduced copayment for those aged $\geq 70$ year olds increased the number of outpatient visits (Shigeoka 2013) and improved their mental health (Nishi et al. 2012). When the copayment exemption for evacuees ended, they may have been reluctant to attend health facilities, and their health status may subsequently have worsened. Improvements in their social capital could conceivably mitigate such problems. For example, previous research showed that community-level social capital mitigated the impact of housing damage on cognitive decline (Hikichi et al. 2018). Hasegawa et al. (2018) reported that social capital enhanced health consultations, as well as disaster preparedness, after the Fukushima disaster.

This study had some limitations. First, we did not include an analysis of data at the level of the individual. Such analyses would enable a more in-depth understanding of the relationship between evacuation and health status. Second, we analyzed only NHI health insurance data. Thus, the data do not include employed citizens and citizens aged $\geq 75$ years, and the results are not applicable to the whole population. Third, we did not stratify the data according to specific diagnoses. Analyses based on diagnostic groups would shed light on the types of diseases related closely to evacuation. Future studies are needed that include individual-level analyses and diagnostic-based data.

Despite these limitations, this study highlights the urgent need for improving the health status of evacuees and for caution in lifting exemptions from copayment.

\section{Acknowledgments}

This study was partly supported by JSPS KAKENHI grant number JP16H05894. We appreciate Dr. Tomoyuki Kobayashi for his advice.

\section{Conflict of Interest}

The authors declare no conflict of interest.

\section{References}

Campbell, D.J., King-Shier, K., Hemmelgarn, B.R., Sanmartin, C., Ronksley, P.E., Weaver, R.G., Tonelli, M., Hennessy, D. \& Manns, B.J. (2014) Self-reported financial barriers to care among patients with cardiovascular-related chronic conditions. Health Rep., 25, 3-12.

Choudhry, N.K., Avorn, J., Glynn, R.J., Antman, E.M., Schneeweiss, S., Toscano, M., Reisman, L., Fernandes, J., Spettell, C., Lee, J.L., Levin, R., Brennan, T. \& Shrank, W.H.; Post-Myocardial Infarction Free Rx Event and Economic Evaluation (MI FREEE) Trial (2011) Full coverage for preventive medications after myocardial infarction. N. Engl. J. Med., 365, 20882097.

Ebner, D.K., Ohsawa, M., Igari, K., Harada, K.H. \& Koizumi, A. 
(2016) Lifestyle-related diseases following the evacuation after the Fukushima Daiichi nuclear power plant accident: a retrospective study of Kawauchi Village with long-term follow-up. BMJ Open, 6, e011641.

Fukunaga, H. \& Kumakawa, H. (2015) Mental health crisis in northeast Fukushima after the 2011 earthquake, tsunami and nuclear disaster. Tohoku J. Exp. Med., 237, 41-43.

Fukushima Prefecture (2018) Transition of evacuation designated zones - Fukushima Prefecture.

https://www.pref.fukushima.lg.jp/site/portal-english/en03-08. html

[Accessed: October 13, 2018].

Fukushima Prefecture (2019) The number of evacuees from Fukushima Prefecture to other Prefecture.

http://www.pref.fukushima.lg.jp/site/portal/ps-kengai-hinan syasu.html

[Accessed: March 19, 2019] (in Japanese).

Hamano, T., Takeda, M., Tominaga, K., Sundquist, K. \& Nabika, T. (2017) Is accessibility to dental care facilities in rural areas associated with number of teeth in elderly residents? Int. J. Environ. Res. Public Health, 14, E327.

Hasegawa, M., Murakami, M., Takebayashi, Y., Nomura, S. \& Tsubokura, M. (2017) Change of costs of medical and nursing cares before and after the Great East Japan Earthquake in Fukushima Prefecture. Proceedings of the SRA-Japan 30th Annual Meeting, Hikone, p.157 (in Japanese).

Hasegawa, M., Murakami, M., Takebayashi, Y., Suzuki, S. \& Ohto, H. (2018) Social capital enhanced disaster preparedness and health consultations after the 2011 Great East Japan Earthquake and nuclear power station accident. Int. J. Environ. Res. Public Health, 15, E516.

Hikichi, H., Aida, J., Matsuyama, Y., Tsuboya, T., Kondo, K. \& Kawachi, I. (2018) Community-level social capital and cognitive decline after a natural disaster: a natural experiment from the 2011 Great East Japan Earthquake and Tsunami. Soc. Sci. Med., doi: 10.1016/j.socscimed.2018.09.057 [Epub ahead of print].

Hirono Town (2017) Existing state of reconstruction in Hirono Town.

http://www.reconstruction.go.jp/topics/main-cat1/sub-cat1-4/ f12fup/20160520 shiryo3-4.pdf

[Accessed: April 20, 2019] (in Japanese).

Kent, S., Fusco, F., Gray, A., Jebb, S.A., Cairns, B.J. \& Mihaylova, B. (2017) Body mass index and healthcare costs: a systematic literature review of individual participant data studies. Obes. Rev., 18, 869-879.

Maciejewski, M.L., Bryson, C.L., Perkins, M., Blough, D.K., Cunningham, F.E., Fortney, J.C., Krein, S.L., Stroupe, K.T., Sharp, N.D. \& Liu, C.F. (2010) Increasing copayments and adherence to diabetes, hypertension, and hyperlipidemic medications. Am. J. Manag. Care, 16, e20-34.

Matsuyama, Y., Tsuboya, T., Bessho, S.I., Aida, J. \& Osaka, K. (2018) Copayment exemption policy and healthcare utilization after the Great East Japan Earthquake. Tohoku J. Exp. Med., 244, 163-173.

Minamisoma City (2019) Residents state in evacuation ordered areas - Minamisoma City.

https://www.city.minamisoma.lg.jp/portal/admin/tokeijoho/ 5307.html

[Accessed: April 20, 2019] (in Japanese).

Ministry of Economy, Trade and Industry (2018) Information regarding the evacuation order up to this point (METI/ Ministry of Economy, Trade and Industry). http://www.meti.go.jp/earthquake/nuclear/hinan_history.html [Accessed: November 15, 2018] (in Japanese).

Ministry of Health, Labour and Welfare (2018a) Survey of national health insurance.

http://www.mhlw.go.jp/stf/seisakunitsuite/bunya/iryouhoken/ database/seido/kokumin jitai.html
[Accessed: February 21, 2018] (in Japanese).

Ministry of Health, Labour and Welfare (2018b) Business report of long-term care insurance.

http://www.mhlw.go.jp/toukei/list/84-1.html

[Accessed: February 15, 2018] (in Japanese)

Ministry of Health, Labour and Welfare (2018c) Analysis of regional differences in expenditure on healthcare.

http://www.mhlw.go.jp/stf/seisakunitsuite/bunya/kenkou iryou/iryouhoken/database/iryomap/index.html [Accessed: February 15, 2018] (in Japanese).

Ministry of Health, Labour and Welfare (2018d) Survey of medical institutions. https://www.mhlw.go.jp/toukei/list/79-1.html [Accessed: April 8, 2019] (in Japanese).

Ministry of Health, Labour and Welfare (2018e) Survey of physicians, dentists and pharmacists. https://www.mhlw.go.jp/toukei/list/33-20.html [Accessed: April 8, 2019] (in Japanese).

Ministry of Health, Labour and Welfare (2018f) Survey of longterm care facilities.

https://www.mhlw.go.jp/toukei/list/24-22-2.html [Accessed: April 20, 2019] (in Japanese).

Ministry of Internal Affairs and Communications (2018) Demographic survey based on basic resident register.

http://www.soumu.go.jp/main_sosiki/jichi_gyousei/daityo/ jinkou_jinkoudoutai-setaisuu.html [Accessed: April 8, 2019] (in Japanese).

Morita, T., Leppold, C., Tsubokura, M., Nemoto, T. \& Kanazawa, Y. (2016) The increase in long-term care public expenditure following the 2011 Fukushima nuclear disaster. J. Epidemiol. Community Health, 70, 738.

Murakami, M., Tsubokura, M., Ono, K., Nomura, S. \& Oikawa, T. (2017) Additional risk of diabetes exceeds the increased risk of cancer caused by radiation exposure after the Fukushima disaster. PLoS One, 12, e0185259.

Nishi, A., McWilliams, J.M., Noguchi, H., Hashimoto, H., Tamiya, N. \& Kawachi, I. (2012) Health benefits of reduced patient cost sharing in Japan. Bull. World Health Organ., 90, 426435A.

Nishide, A., Fujita, M., Sato, Y., Nagashima, K., Takahashi, S. \& Hata, A. (2017) Income-related inequalities in access to dental care services in Japan. Int. J. Environ. Res. Public Health, 14, 524.

Nomura, S., Blangiardo, M., Tsubokura, M., Ozaki, A., Morita, T. \& Hodgson, S. (2016) Postnuclear disaster evacuation and chronic health in adults in Fukushima, Japan: a long-term retrospective analysis. BMJ Open, 6, e010080.

Ohira, T., Nakano, H., Nagai, M., Yumiya, Y., Zhang, W., Uemura, M., Sakai, A. \& Hashimoto, S.; Fukushima Health Management Survey Group (2017) Changes in cardiovascular risk factors after the Great East Japan Earthquake. Asia Pac. J. Public Health, 29, 47S-55S.

Reconstruction Agency (2019) A survey to measure local feelings in evacuation ordered areas. http://www.reconstruction.go.jp/topics/main-cat1/sub-cat1-4/ ikoucyousa/ [Accessed: April 20, 2019] (in Japanese).

Shigeoka, H. (2013) The effect of patient cost sharing on utilization, health, and risk protection. NBER Working Paper, No. 19726

Statistics Bureau, Ministry of Internal Affairs and Communications (2017) Result of 2017 national population census. http://www.stat.go.jp/data/kokusei/2015/kekka.html [Accessed: April 30, 2018] (in Japanese).

Tsuboya, T., Aida, J., Hikichi, H., Subramanian, S.V., Kondo, K., Osaka, K. \& Kawachi, I. (2017) Predictors of decline in IADL functioning among older survivors following the Great East Japan Earthquake: a prospective study. Soc. Sci. Med., 176, 34-41. 
Uchimura, M., Kizuki, M., Takano, T., Morita, A. \& Seino, K. (2014) Impact of the 2011 Great East Japan Earthquake on community health: ecological time series on transient increase in indirect mortality and recovery of health and long-term-care system. J. Epidemiol. Community Health, 68, 874-882.

Yoshida, K., Shinkawa, T., Urata, H., Nakashima, K., Orita, M., Yasui, K., Kumagai, A., Ohtsuru, A., Yabe, H., Maeda, M.,
Hayashida, N., Kudo, T., Yamashita, S. \& Takamura, N. (2016) Psychological distress of residents in Kawauchi village, Fukushima Prefecture after the accident at Fukushima Daiichi Nuclear Power Station: the Fukushima Health Management Survey. PeerJ, 4, e2353. 